\title{
Aplicação de Poka Yoke em processos de caldeiraria
}

\author{
Josiel Teixeira Consul ${ }^{\text {** }}$ \\ ${ }^{\mathrm{a} *}$ Centro Universitário Metodista-IPA, Porto Alegre, RS, Brasil, josielkons@yahoo.com.br
}

\begin{abstract}
Resumo
Como objetivo, este artigo pretende identificar como o método Poka Yoke contribui para evitar erros, corrigindo defeitos na execução de peças caldeiradas. Como justificativa para a escolha desse tema destaca-se que as empresas cada vez mais investem na qualidade de seus processos de produção, sendo o desperdício algo que sinaliza falhas e que os mecanismos de averiguação dos meios de controle necessitam ser cada vez mais aprimorados. A linha de pesquisa utilizada para tal estudo está na sistematização in loco de como se dará o fluxo do processo do método Poka Yoke na sua aplicação em peças caldeiradas. A metodologia será em etapas definidas de controle, incluindo avaliação quantitativa e qualitativa dos erros, identificando-se os processos de falhas, bem como melhorias de produção, bem como avaliando como se dá o retrabalho e de maneira esse se dá no processo de controle de eficácia da linha de produção. Cabe ressaltar que este trabalho destina-se à instrumentalização de que a Engenharia de Produção se apropria e utiliza no que se refere ao desenvolvimento voltado ao processo de gestão, incluindo-se assim o foco principal de formação que a instituição particulariza. Foi visto na pesquisa que o sistema funciona ainda mais quando há uma conscientização dos trabalhadores para a importância da metodologia aplicada nos processos de produção.
\end{abstract}

Palavras-chave

Poka Yoke. Produção enxuta. Qualidade.

\section{Introdução}

No cenário econômico atual, as empresas de todos os segmentos buscam diminuir custos de fabricação terceirizando processos de produção uma vez que insumos e mão de obra sejam menos dispendiosos. Geralmente, esses processos de terceirização são desenvolvidos por empresas de menor porte. Essa busca tem como objetivo aumentar a produtividade com a diminuição de tempo de produção, de estoques e de insumos.

Entre as alternativas utilizadas para a otimização de peças caldeiradas está a terceirização, que agilizou o repasse de serviços buscando a relação entre custo e benefício. A vantagem do processo de terceirização está na possibilidade de reduzir custos e concentrar forças no ramo da atividade desenvolvida. Gerar atrativos para combater as possíveis fontes de desperdício é um dos objetivos da terceirização, garantindo economia do processo de produção e que o mesmo mantenha-se de maneira mais eficiente.

No processo de fabricação de muitas empresas, principalmente as do setor metal-mecânico, o que mais onera tempo e mão de obra são os processos caldeirados, que exigem a terceirização de serviços, envolvem a conformação mecânica de corte, dobra e soldagem de chapas. Existe uma grande dificuldade para atingir qualidade e boa estabilidade dimensional nesse tipo de manufatura, o que requer melhorias no processo, que possibilitem a eliminação de inspeções e diminuição dos retrabalhos através da garantia da qualidade. Isso seria atingido determinando-se quais são os parâmetros de manufatura responsáveis pela produção de peças em conformidade e monitorando-se e ajustando-se criteriosamente cada operação, no sentido de observarem-se os parâmetros mínimos exigidos. Um dos principais problemas em se adquirir estabilidade dimensional nas peças caldeiradas está no processo de conformação e soldagem, pois nele ocorre uma grande variação térmica, que pode levar à instabilidade dimensional da peça, acarretando assim perdas ou retrabalhos. Caso o custo deste retrabalho, quando absorvido pela empresa que terceiriza esse processo, seja repassado ao cliente de forma negativa, a empresa poderá perder a confiança do cliente e isso 
consequentemente prejudicará os lucros e perderá critérios de qualidade.

Então, nesse contexto, para se adquirir produtividade, qualidade e estabilidade dimensional, em processos de fabricação de peças caldeiradas em empresas de pequeno porte, torna-se necessário a aplicação de métodos para prevenção de erros. Será apresentada neste trabalho a aplicabilidade dos dispositivos à prova de falhas (Poka Yoke) na linha de produção, bem como a sua importância no contexto da qualidade na manufatura, e como esse método é desenvolvido.

A questão a ser desenvolvida ao longo deste trabalho traz a discussão de como o método pode ser utilizado nos processos de peças de caldeiraria, definindo de que forma são utilizadas as suas normas de aplicação para redução de custos e danos. Com isso acredita-se que a implantação de dispositivos Poka Yoke pode ampliar o esforço no desenvolvimento de soluções eficazes que garantam a boa qualidade, reduzindo falhas ou acidentes em processos e em produtos e mantendo a satisfação nos serviços prestados. Para garantir um produto totalmente isento de defeitos é necessário controlar a variabilidade do processo, as fontes de defeitos, incluindo-se a complexidade que envolve erros e falhas, apresentando o processo de mecanismos de verificação e análise da qualidade. Com base nisso tem-se a questão de pesquisa: Como o método Poka Yoke pode evitar a ocorrência de possíveis defeitos em processos de fabricação de peças caldeiradas?

Como objetivo, este artigo pretende identificar como o método Poka Yoke contribui para evitar erros, corrigindo defeitos na execução de peças caldeiradas. Como justificativa para a escolha desse tema destaca-se que as empresas cada vez mais investem na qualidade de seus processos de produção, sendo o desperdício algo que sinaliza falhas e que os mecanismos de averiguação dos meios de controle necessitam ser cada vez mais aprimorados.

Destaca-se o aumento da concorrência mundial e o fenômeno da globalização da economia, que passaram a provocar mudanças importantes no setor de desenvolvimento de produtos com maiores critérios de qualidade em sua manufatura. Tais mudanças estão relacionadas com a constante busca por maior flexibilidade e qualidade, bem como com a redução de custos e a otimização entre custo e benefício. As indústrias aderem cada vez mais à utilização de dispositivos destinados à manutenção da qualidade, que devem envolver a aplicação e implantação de métodos a prova de falhas, que determinem condições de qualidade de produtos fornecidos, em um contexto que garanta os critérios exigidos na pemanente garantia de qualidade.
Partindo desse princípio encontra-se o Poka Yoke, método que possibilita o suporte à resolução de problemas e o controle de maneira criteriosa dos defeitos, auxiliando nos processos produtivos ante possiveis falhas. Trata-se de uma abordagem já adotada por empresas japonesas desde a década de 1960 como importante meio de alcançar o desejado zero defeito, bem como garantir inspeções para o controle de qualidade esperada.

Diz Ghinato (1996) que as falhas humanas são inerentes ao processo produtivo e necessitam serem associadas à aplicação do Poka Yoke, prevenindo-se assim que tais debilidades manifestem-se e assim evitando-se que sucessivos defeitos ocorram na linha de produção. Segue também neste trabalho a discussão sobre a terceirização dos processos de produção, que vem a ser uma importante alternativa que oportuniza empresas de médio e pequeno porte na absorção da produção de peças caldeiradas, mantidos critérios e parâmetros de qualidade.

Para que isso ocorra, o retrabalho necessita ser evitado, aplicando-se métodos de controle que viabilizem maior qualidade, produtividade, bem como lucros, para que tal repasse de serviços mantenha soluções eficazes que garantam a otimização dos processos utilizados. Cada organização implementa sua forma de gestão da qualidade e utiliza sistemas e planejamento para a melhoria estratégica na organização de seus recursos de capital, que permitam a criação de processos de qualidade dos produtos acabados, para garantir melhor competitividade no setor econômico, bem como melhorar sua visibilidade no mercado. Os processos de gestão e a sua maneira de avaliação, controle e melhoria devem estar de acordo com os princípios e fundamentos de gestão da qualidade, adequando cada vez mais métodos, ferramentas e técnicas.

Essa forma de estratégia de gestão para o futuro das empresas leva ao aumento da eficiência da organização e preservação da sua posição no mercado. 0 objetivo do Poka Yoke, eliminar ou minimizar erros humanos nos processos de fabricação e gestão, está incluído no processo de maior qualidade, contribuindo para a eficácia e economia da empresa. Para isso é essencial eliminar erros a fim de prevenir as causas de tais falhas e utilizar este sistema de controle, que é relativamente barato e comprometido com os fluxos de produção de maneira otimizada.

É de extrema importância que a Engenharia de Produção se aproprie cada vez mais dos processos que especifiquem a qualidade, identificando que nos fluxos de produção estão inclusos erros, retrabalho e falhas que gravam o aumento da produtividade e, consequentemente, a redução de custos. A partir da necessidade, entre questões práticas e teóricas, 
neste trabalho busca-se discutir alguns conceitos nos quais são direcionados procedimentos de avaliação e manutenção de critérios de qualidade, fazendo-se necessário definir conceitos e, principalmente, sua forma de aplicação dentro da realidade que o processo de produção exige.

A linha de pesquisa utilizada para tal estudo está na sistematização in loco de como se dará o fluxo do processo do método Poka Yoke na sua aplicação em peças caldeiradas. A metodologia será em etapas definidas de controle, incluindo avaliação quantitativa e qualitativa dos erros, identificando-se os processos de falhas, bem como melhorias de produção, bem como avaliando-se como se dá o retrabalho e de que maneira ele acontece no processo de controle de eficácia da linha de produção. Cabe ressaltar que este trabalho destina-se à instrumentalização de que o curso de Engenharia de Produção do Centro Universitário Metodista-IPA se apropria e utiliza no que se refere ao desenvolvimento voltado ao processo de gestão, incluindo-se assim o foco principal de formação que a instituição particulariza. Assim, de forma criativa, direcionam-se e se oferecem alternativas para o conhecimento, interagindo-se com a questão do fluxo eficiente que a economia oferece no contexto socioeconômico, no qual as empresas estão inseridas, amplo mercado de trabalho destinado à Engenharia de Produção.

\section{Fundamentação teórica}

\subsection{Sistema Toyota de Produção}

O Sistema Toyota de Produção, o STP, surgiu na empresa Toyota, no Japão, logo após a Segunda Guerra Mundial. 0 produto mais visível na Toyota é a sua filosofia, ou seja, o STP. Esse sistema é a segunda evolução em processos administrativos eficientes depois do sistema de produção em massa inventado por Henry Ford e já foi documentado, analisado e exportado para empresas de diferentes indústrias de todo mundo (Liker, 2005). Tal sistema surgiu da necessidade de eliminação de perdas e sua implementação começou logo após a Segunda Guerra Mundial. Nessa época, a indústria japonesa mantinha uma produtividade baixa e padecia de uma grande falta de recursos, o que a impossibilitava de aderir ao modelo da produção em grande escala (Ohno, 1997).

Nas visitas às fábricas da Ford para analisar o modelo de produção em massa, Toyoda e Ohno verificaram que o mercado restrito e com demandas incipientes não suportaria o fluxo de produção. Assim, para manter-se, os gerentes notaram a necessidade de fazer uma adaptação ao mercado japonês, contrastando com a filosofia da empresa Ford no contexto da época, caracterizado pelos baixos volumes e com diversificados modelos utilizando a mesma linha de produção. 0 mercado japonês exigia qualidade, baixo custo, lead-time (o tempo de processamento de um pedido) curto e grande flexibilidade (Ohno, 1997). 0 Sistema Toyota de Produção da forma como ele é hoje começou a tomar forma após a Segunda Guerra Mundial, mas demorou mais de 20 anos para ser consolidado. No entanto, diversos princípios e mecanismos do sistema surgiram ainda no começo do século, através da genialidade de seus primeiros dirigentes.

A fábrica da Toyota despontou no mercado mundial como uma das principais montadoras de automóveis. Esse sucesso é proveniente do desenvolvimento e da implementação de um sistema de produção que levou não somente a Toyota mas diversas outras empresas japonesas a um período de grande crescimento econômico. Os princípios, conceitos e técnicas de manufatura que estavam por trás desse sistema tornaram-se conhecidos como Sistema Toyota de Produção (Antunes, 1998).

0 Sistema Toyota de Produção é um sistema de gerenciamento da produção que tem como objetivo principal aumentar o lucro através da constante redução de custos. Para que esse objetivo seja alcançado, é necessário identificar e eliminar as atividades que não agregam valor ao produto. Essas atividades são identificadas como "perdas" do processo produtivo (Ghinato, 1996).

Sellito (2000) relata que executivos de outras áreas, tomando conhecimento do STP e seus princípios, buscam fazer uma aplicação dessa nova lógica. Há um grande interesse em relação ao STP e seus resultados. Para conhecê-lo, é essencial o entendimento dos conceitos básicos do sistema e de suas implicações. Sem que isso aconteça, não serão obtidos resultados realmente eficazes na administração da produção baseada no STP (Shingo, 1996).

Apresentam-se a seguir alguns conceitos do Sistema Toyota de Produção, identificando-se uma de suas principais ferramentas, o chamado Kanban, sendo aqui também revisados os conceitos relacionados aos pilares que sustentam o STP: just-in-time e autonomação, e os princípios básicos desse sistema.

De acordo com Ohno (1997), a ferramenta usada para operar o Sistema Toyota de Produção é o Kanban. Trata-se de uma palavra japonesa que significa registro, esse registro é usado mais frequentemente na forma de cartões, dentro de um envelope de vinil retangular. Nesse pedaço de papel, a informação pode ser dividida em três categorias: (1) informação de coleta, (2) informação de transferência e (3) informação de produção. 
Outra ferramenta importante é o método Poka Yoke, termo que em japonês significa evitar ou prevenir erro. Portanto, pode ser definido como uma ferramenta à prova de erros ou isenta de falhas, constituída de técnicas utilizadas para evitar simples erros humanos no trabalho. 0 termo pode ser entendido, então, como qualquer dispositivo que auxilie na prevenção de falhas e erros em processos produtivos (Costa Junior, 2007).

0 Sistema Toyota de Produção busca reduzir as ineficiências da produção, que não só prejudicam os resultados, mas também são consideradas fontes causadoras de falta de organização, o que, consequentemente, tem impacto direto no ambiente de trabalho, portanto é necessária a busca de soluções não geradoras de desperdícios (Costa Junior, 2007).

A base de sustentação do Sistema Toyota de Produção é a absoluta eliminação do desperdício e os dois pilares necessários à sua sustentação são o justin-time e a autonomação (Fusco \& Sacomano, 2007).

Just-in-time, o JIT, é o elemento que mais se destaca dentro dos princípios da produção enxuta. Amplamente estudado e discutido, o JIT prega que cada processo deve ser abastecido com as necessidades certas e no momento certo, sem apresentar erros quanto à quantidade e ao local de entrega. Com isso, ele identifica, localiza e elimina perdas, garantindo o fluxo contínuo no chão de fábrica (Shingo, 1996). São atribuídas ao JIT as ferramentas de fluxo contínuo, takt-time, produção puxada e kanban (Ghinato, 1996).

0 Sistema Toyota de Produção ganhou notoriedade nos meios acadêmicos e industriais de todo o mundo, em grande parte devido ao impacto do just-in-time sobre os métodos de gerenciamento existentes até então.

Outra base do pilar de sustentação do STP é a autonomação, ou "jidoca”, como também é conhecido (Ghinato, 1996). Na verdade, essa palavra significa simplesmente autonomação. "Ninben no aru jidoca" expressa o verdadeiro significado do conceito, ou seja, que a máquina é dotada de inteligência e toque humano. A autonomação é muitas vezes expressa como simplesmente automação com toque humano e a palavra 'jidoca' também é usada, simplificadamente, com esse mesmo significado. Shingo prefere a expressão "pré-automação", uma vez que somente a correção do problema é deixada a cargo do operador (Ghinato, 1996).

\subsection{O método Poka Yoke}

Para operacionalizar o Controle de Qualidade Zero Defeitos (CQZD), foram criados na Toyota Motor Company, em 1961, os dispositivos de detecção de anormalidade denominados Poka Yoke. 0 objetivo dos Poka Yokes é viabilizar a inspeção 100\% na fonte, com feedback rápido e, consequentemente, eliminar a perda decorrente da fabricação de produtos defeituosos. Tais dispositivos são particularmente importantes quando o objetivo é o controle de qualidade com zero defeito. Eles são, em sua maioria, utilizados para garantir um processamento livre de falhas, mas podem também ser aplicados às operações de transporte, inspeção e estocagem (Ghinato, 1996). Os dispositivos Poka Yoke também estão presentes na automação.

A ideia da utilização de dispositivos Poka Yoke surgiu a partir da invenção do tear autoativado, por Sakichi Toyoda. 0 tear era uma máquina que, através de um dispositivo Poka Yoke, parava quando alguma anormalidade acontecia. Isso possibilitava a um único operário cuidar de várias máquinas ao mesmo tempo. A detecção de anormalidades no processo, a interrupção desse processo e a correção da anormalidade dependem, em grande parte, da utilização desses dispositivos (Ghinato, 1996).

No Japão, do início do século XX, Sakichi Toyoda inventou o que pode ser considerado o primeiro dispositivo Poka Yoke: um mecanismo que, acoplado a peças, era capaz de identificar defeitos, o que identificaria a necessidade de paralisação da operação de forma imediata. Esse simples mecanismo possibilitou que tal processo fosse operado por um único trabalhador, o que evidenciou uma grande vantagem competitiva naquela época.

O conceito do método eficiente e capaz de detectar uma anormalidade no processamento foi posteriormente difundido na Toyota Motor Company por Taiichi Ohno. Shigeo Shingo, consultor da Toyota durante anos, encarregou-se de aprimorar esse conceito e levá-lo para várias indústrias. Conforme Ghinato (1996), o Poka Yoke é mais do que apenas um mecanismo de detecção de erros ou defeitos, é um recurso utilizado com o principal objetivo de apontar ao operador (ou à máquina) a maneira mais adequada de realizar tal operação. É, em resumo, uma forma de bloquear as principais interferências (normalmente erros humanos) na execução da operação.

Esses dispositivos são em, sua grande maioria, utilizados para garantir um processamento livre de falhas, mas podem também ser aplicados com muito sucesso acoplados às operações de transporte, inspeção e até estocagem. Dessa forma o Sistema Poka Yoke abrange fundamentos, conceitos e metodologia de aplicação nos mais diversos sistemas e processos da empresa. 0 dispositivo Poka Yoke é um componente fundamental das práticas de controle da qualidade na Toyota: o Controle da Qualidade Zero Defeitos (CQZD). 0 CQZD visa à eliminação total dos defeitos a partir da identificação e bloqueio de sua causa, os 
erros. 0 CQZD pode ser definido como a aplicação de dispositivos Poka Yoke em regime de inspeção 100\%, na fonte dos defeitos, gerando feedback e ação corretiva imediatos (Ghinato, 1996).

o Sistema Poka Yoke, em função de suas características, pode ser classificado de diversas maneiras. Shingo o classifica de acordo com o propósito e técnicas utilizadas. Monden (1984) adota uma classificação similar a essa, porém ele não considera a distinção que Shingo faz entre propósitos e técnicas. Apresenta os métodos de contato, conjuntos e etapas como classes de dispositivos utilizados nos sistemas a prova de erro. A função de regulagem define o método a ser utilizado em função do objetivo pretendido.

Ou seja, depois de detectada uma anormalidade, o Sistema Poka Yoke pode bloquear o processamento ou apenas avisar a ocorrência da anormalidade, dependendo da gravidade, frequência e/ou consequência do problema.

a) Método do Controle: Após detectar uma anormalidade, o sistema para a linha ou a máquina de forma que a ação corretiva seja imediatamente implementada evitando-se a geração de defeitos em série. O CQZD depende da ampla utilização desse método.

b) Método da Advertência: 0 sistema detecta a anormalidade, mas ao invés de parar o processamento, apenas sinaliza a ocorrência do desvio através de sinais sonoros ou sinais luminosos, de forma que a atenção dos responsáveis seja atraída e as ações corretivas possam ser implementadas a tempo. Como existe a possibilidade de o sinal ser negligenciando e o processo continuar produzindo sob condições precárias, esse método deve ser utilizado somente em situações em que o impacto das anormalidades seja comprovadamente reduzido ou quando a implantação de controle for técnica ou economicamente inviável.

c) Método do Contato: Esse método detecta a anormalidade na forma de dimensão e presença de tipos específicos de defeitos através de dispositivos que se mantêm em contato com o produto na ocasião da inspeção.

d) Método do Conjunto: Esse método é utilizado em operações numa sequência de movimentos ou passos pré-estabelecidos, garantindo que nenhum desses passos seja negligenciado. Normalmente, o método baseia-se na contagem automática e controle do número de movimentos realizados ou na detecção da execução de cada um dos passos isoladamente.

e) Método das Etapas: Esse método, em que a operação é executada através de movimentos sincronizados, evita que o operador realize por engano uma etapa que não faz parte da operação.

Seguindo o mesmo autor, além do importante papel na prática do CQZD, o dispositivo Poka Yoke é um elemento essencial na autonomação (jidoka): um dos dois pilares do Sistema Toyota de Produção, que consiste em facultar ao operador ou à máquina a autonomia de parar o processamento sempre que for detectada qualquer anormalidade.

Partindo desse princípio, segundo Shingo (1996), inspeção sucessiva, autoinspeção e inspeção da fonte podem ser todas alcançadas por meio do uso do dispositivo Poka Yoke. Esse método possibilita a inspeção 100\% através de controle físico ou mecânico.

Portanto, essa metodologia consiste em formas de garantir a não ocorrência de possíveis defeitos. Os dispositivos ou mecanismos Poka Yoke (na origem, em língua japonesa, yokeru: evitar; poka: erros negligentes), também definidos mecanismos de prevenção de erros, ou à prova de falhas, vêm sendo utilizados sistematicamente pela indústria japonesa. Esse conceito foi aperfeiçoado por Shigeo Shingo como um meio de se atingir o zero defeito e, consequentemente, extinguir as inspeções para o controle da qualidade (Shimbun, 1988).

0 Poka Yoke não é uma forma de inspeção mas um método com abrangência maior de detectar defeitos ou erros, que pode ser usado para alcançar uma determinada função de inspeção. A inspeção realizada é o objetivo a ser definido e o Poka Yoke é o método que define o controle, etapas ou frequência capaz de satisfazer a inspeção esperada (Shingo, 1996).

Um importante método de reparos e de identificação de erros - assim Shingo (1996) o define. Tal processo identifica a causa dos erros que os trabalhadores produzem em peças com defeitos de fabricação e alerta a manutenção desses erros. Poka Yoke, portanto, é um dispositivo à prova de erros destinado a evitar a ocorrência de defeitos em processos de fabricação de produtos, desenvolvido a partir do princípio do custo zero, cuja função é controlar e alertar para a existência do erro, parando a produção para sua correção através dos métodos de sinalização de defeitos.

Um dispositivo Poka Yoke na linha de produção tem como função a paralisação de todo um sistema (por exemplo: máquinas, equipamentos), sendo o controle do produto realizado a partir da sinalização imediata quando ocorre a detecção de algum defeito. Tal processo tem como objetivo a função de prevenir um problema, evitando a sua ocorrência ou detectando-o após o evento, sendo assim caracterizado como Função Reguladora ou Mecanismos de Detecção (Moura \& Banzato, 1996).

\section{Apresentação dos resultados}

\subsection{Pesquisa e coleta de dados}

Este trabalho consiste de uma pesquisa aplicada, caracterizando-se como do tipo exploratório e 
descritivo sobre fatos a serem analisados, bem como identificando os procedimentos de levantamento de campo e observação assistemática. Cabe aqui apresentar que quanto à sua natureza tal pesquisa voltou-se à classificação como aplicada, pois seu objetivo foi gerar conhecimentos para aplicação prática dirigida à solução de problemas específicos, envolvendo verdades e interesses locais (Gil, 2002).

De acordo com seus objetivos e forma de abordagem, a pesquisa destinou-se a estudo qualitativo. Cabe ressaltar que esse estudo buscou uma intervenção in loco com a participação dos trabalhadores na linha de produção ao se aplicar o Método Poka Yoke no processo de obtenção do controle de qualidade, a fim de verificar a existência ou não de erros em peças de caldeiradas. Tal procedimento está de acordo com o problema de pesquisa previamente levantado neste trabalho que, a partir do delineamento de pesquisa, buscou os resultados posteriores na análise de seus conteúdos.

A presente pesquisa voltou-se para os conceitos e a funcionalidade de acordo com o método Poka Yoke, bem como buscou sua definição na revisão bibliográfica e a posterior utilização de seus dispositivos in loco. Inclui-se também o Sistema Toyota de Produção, que foi apresentado conforme seus pilares e princípios.

De acordo com Gil (2002), determinados conceitos são necessários para a organização da pesquisa quanto ao desenvolvimento de conceitos como definição de tempo e espaço. Quanto ao espaço foi aplicado o dispositivo Poka Yoke no setor de caldeiraria a fim de aplicar seus propósitos e técnicas. Foram averiguadas as funções de regulagem (avaliação de presença de anormalidade nas peças e advertências ao erro) e de detecção (contato com o produto durante o processo de inspeção e padronização de movimentos utilizados).

Quanto à amostragem, o trabalho utilizou metodologicamente, por conveniência, a não probabilistica - aquela em que o pesquisador seleciona membros da população que estão mais acessiveis (Schiffman \& Kanuk, 2000). Os participantes da pesquisa foram seis trabalhadores envolvidos com suas tarefas de rotina no setor caldeireiro, partindo-se do princípio de que esses funcionários já possuem conhecimentos prévios em suas atividades.

Coletaram-se dados no setor de caldeiraria da empresa em estudo. Se a inspeção sucessiva, que detecta defeitos depois que eles ocorrem, não for a maneira mais eficaz de eliminar os defeitos naquele processo, outro sistema deve ser usado. Dessa forma, o primeiro passo na escolha e adoção de métodos de controle de qualidade efetivos é identificar o sistema de inspeção que melhor satisfaz as necessidades de um determinado processo.
Foi utilizado nesta pesquisa o tipo de entrevista estruturada, elaborada conforme o que se pretendeu avaliar, e o entrevistado colocou-se diante do que foi analisado de maneira participante. Assim, o controle de qualidade e o uso do método Poka Yoke para avaliar a presença de erros no processo de produção de peças caldeiradas contou com a experiência dos trabalhadores (os participantes do estudo), bem como observou o processo de manufatura e a especificidade de mão-de-obra.

0 tipo de observação foi a não estruturada, em que foi organizado um diário de campo com a finalidade de registrar o que era analisado, para que o conteúdo pudesse emergir através da experiência in loco.

Através da perspectiva de pesquisa qualitativa realizou-se a técnica de análise de conteúdo a partir do que foi respondido na entrevista individual e questionários dos participantes. Foi realizada uma avaliação das respostas, fazendo-se uma correlação do tema de pesquisa anteriormente proposto neste estudo. Com o embasamento teórico assim definido nesta pesquisa foi feita a análise qualitativa das entrevistas, proporcionando uma comparação dos resultados e o uso de análise de conteúdo.

\subsection{Resultados e discussão}

Os resultados foram analisados de acordo com cada quesito avaliado, tendo por base os conceitos descritos na seção 2.

Para Vergara (2003), a análise de conteúdo é considerada uma técnica para o tratamento de dados que visa identificar o que está sendo dito a respeito de determinado tema.

0 dispositivo que pretende ser à prova de erros é importante especialmente na condução de processos, em termos de metodologia, para que os operadores não incorram em enganos que possam comprometer a qualidade dos produtos.

Durante a pesquisa foram identificadas falhas no processo de produção, em especial na obtenção do dimensional de peças caldeiradas em que não foram usados dispositivos Poka Yoke, essas falhas implicavam perda total da manufatura. 0 retrabalho das peças caldeiradas que eram produzidas sem o uso de Poka Yokes, por ter o seu dimensional não conforme, era descartado, não podendo elas serem recuperadas.

A gestão da qualidade e o enfoque por processos são aplicáveis a todos os tipos de organização, seja qual for sua natureza. Em relação aos serviços de informação, sugere-se que os gestores analisem a aplicação dos princípios da gestão da qualidade tomando por base a consideração de que o estabelecimento de um canal efetivo de comunicação com seus usuários, visando 
a captar, tratar e gerenciar a satisfação dos clientes internos e externos, é importante (Valls, 2004). Nesse sentido, o Poka Yoke torna os processos e rotinas de produção mais seguros.

A aplicação do Método Poka Yoke nesta pesquisa buscou também a qualidade da manufatura, pois a qualidade do produto é definida quando um conjunto de especificações do produto são previamente definidas e a qualidade passa a ser avaliada pelo grau de conformidade das especificações do produto real com as especificações do projeto (Almeida \& Toledo, 1992).

Todos os itens produzidos durante esta pesquisa foram verificados somente no final do processo produtivo, na linha de produção, sendo analisados de acordo com o desenho do cliente, onde o dimensional era todo verificado de acordo com as tolerâncias contidas no seu desenho.

A competitividade é fator de importância para o sucesso das organizações, sendo que a implantação de um sistema de qualidade "[...] pode ser um diferencial e uma vantagem competitiva na busca pela participação no mercado" (Rebelato \& Oliveira, 2006, p. 106).

Outro conceito importante é o de melhoria contínua, percebido no decorrer das entrevistas realizadas. Relacionado ao TQM, é o conceito de kaizen, ou melhoria contínua. Kaizen significa melhoria incremental contínua dos processos de qualidade e produtividade para ajudar a atender as metas organizacionais (Monden et al., 1984; Imai, 1996).

Kaizen também incorpora ideias de funcionários e participação para ajudar a realizar essas melhorias incrementais. Uma parte importante do kaizen é a melhoria do fluxo de trabalho para facilitar um processo de produção lisa, que é produtiva e promove produtos de qualidade.

Portanto, os conceitos de satisfação do consumidor e melhoria contínua são a base para as seguintes estratégias: definição de competências essenciais e maximização do capital e da produtividade do trabalho (eficiência), apontando para zero defeito de qualidade nas atividades organizacionais (qualidade) de grandes dimensões; otimização de tempo de espera total (tempo de entrega); organização e controle de insumos de produção e as saídas, a fim de lidar com a demanda do mercado diversificado e flutuante (flexibilidade); e organização e controle do projeto e desenvolvimento de produtos, a fim de antecipar e responder em tempo hábil às condições de mercado (inovação).

Atualmente há muitas definições para essa forma de produção. Assim como Paradigma Estratégico de Gestão da Manufatura (PEGEM) define a manufatura enxuta como um modelo estratégico e integrado de gestão, direcionado a certas situações de mercado, que se propõe a auxiliar a empresa a alcançar determinados objetivos de desempenho em termos de qualidade e produtividade (Godinho Filho \& Fernandes, 2004, p. 1).

Dois conceitos básicos nesse tipo de produção são: eliminar resíduos e criar valor. Como com qualquer outra iniciativa de mudança, implementações diferem muito de uma empresa para outra. Alguns dos problemas e as discrepâncias podem ser atribuídos a diferenças no segmento de mercado, processos de produção e competitividade e regulamentação ambiental. No entanto, parece razoável suspeitar que mudanças tão grandes quanto uma magra implementação são muito influenciados pela cultura da empresa, seus valores e tradições (Manotas-Duque \& Rivera-Cadavid, 2007).

Segundo Womack \& Jones, a mentalidade enxuta é um conjunto de práticas de gerenciamento oriundos da dificuldade de as empresas manterem a lógica da produção em massa. Conforme Womack \& Jones (2004), técnicas como a reengenharia , a analise de valor, foram codificadas na forma de mentalidade enxuta, resumidas e divididas em cinco princípios.

Assim, o questionário aplicado aos trabalhadores contempla método de contato, método de conjunto e das etapas, tendo sido utilizado o seguinte parâmetro citado de Silva (2009) (Tabela 1).

0 checklist de organização é a lista de prioridades, tal como expressas na missão da organização e na visão, elaborada pela equipe durante o processo de planejamento.

As ferramentas de melhoria de qualidade são úteis na identificação de problemas e análise. Técnicas de resolução que são úteis para melhorar a produtividade, qualidade e desempenho são discutidas. Decidir quando o problema ocorre com mais frequência, ou qual é o mais importante e quando será abordado em primeiro lugar. Definir qual, incluindo onde e quando ocorre e a extensão dele. Desenvolver uma lista completa de todas as possíveis causas e decidir sobre a causa raiz e não apenas sobre o sintoma. Escolher uma solução viável e desenvolver um plano de ação para implementar a solução. Implementar a solução e follow-up (acompanhamento e relatório de resultados) (Untawale \& Akant, 2009).

Eliminar o desperdício ao longo dos fluxos de valores inteiros em vez de em pontos isolados, criar processos que necessitam de menos esforço humano, menor espaço, menor capital e tempo para fazer produtos e serviços a um custo muito menor e com defeitos muito menores em comparação com os sistemas de negócio tradicionais. As empresas são capazes de responder aos desejos do cliente e mudar com variedade, alta qualidade, baixo custo e com 
Tabela 1. Métodos de Poka Yoke.

a) 0 método de contato identifica os defeitos em virtude da existência ou não de contato entre o dispositivo e alguma característica ligada à forma ou dimensão do produto. (Às vezes são feitas pequenas mudanças na dimensão ou forma do produto, de forma que os defeitos sejam mais facilmente identificados.)

b) 0 método de conjunto determina se um dado número de atividades previstas são executadas.

c) 0 método das etapas determina se são seguidos os estágios ou operações estabelecidos por um dado procedimento (Shingo, 1986 apud Silva, 2009).

a) Quando a implantação envolver melhoria contínua:

- 0 time de trabalho é responsável pelo desenvolvimento, instalação e validação do dispositivo;

- A engenharia da qualidade deve controlar a codificação e preencher os registros de controle de dispositivos.

b) Quando a implantação estiver relacionada com um produto em desenvolvimento:

- 0 time de trabalho é responsável pelo desenvolvimento, instalação e validação do dispositivo;

- A engenharia da qualidade deve controlar a codificação e preencher os registros de controle de dispositivos;

- A engenharia de manufatura deve atualizar a documentação do Plano de Qualidade, Instruções de Processo e PFMEA.

Fonte: Silva (2009, p. 41).

Tabela 2. Questionário estruturado sobre o Método Poka Yoke.

No quesito método de contato, o trabalhador consegue identificar os defeitos em razão de dispositivo de contato ou forma do produto, eliminando o defeito na fabricação?

(sim)

(não)

Observações:

No quesito método de conjunto existe um número de atividades a serem cumpridas? Todas elas são executadas de acordo com o planejamento de produção?

(sim)

(não)

Observações:

No quesito método são seguidos os estágios ou operações estabelecidos pelo planejamento da produção?

(sim)

(não)

Observações:

Fonte: Silva (2009, p. 41).

tempos de processamento muito rápido. Além disso, a gestão da informação torna-se precisa.

0 Tabela 2 aborda o método de conjunto em que se examina cuidadosamente todos os passos que são necessários para trazer um novo produto ou serviço a partir da ideia de produção, desde a encomenda até a entrega e da matéria-prima ao produto final entregue.

Essas etapas podem ser perfeitamente realizadas, incluindo todas as partes envolvidas. Todos os processos são examinados continuamente de acordo com a definição do cliente de valor e sem valor agregado e os resíduos são atividades com força e metodicamente eliminada. (Abdulmalek \& Rajgopal, 2007).

Com a aplicação dos questionários foram obtidas tabelas de respostas para os seis trabalhadores entrevistados, tendo sido elaborados gráficos.

Sabe-se que uma produção com zero defeito é uma ferramenta poderosa que, quando aprovada pode criar excelentes resultados financeiros e operacionais. Gestores, no entanto, têm sido relutantes em adaptar as ferramentas de manufatura enxuta para a indústria de processo devido às características distintivas da indústria de processo. A revisão da literatura sugere que as abordagens JIT e kanban têm sido aplicadas em algumas instalações de processamento e que bons resultados têm sido relatados. Por outro lado, a literatura sugere que ninguém teria examinado sistematicamente o uso de ferramentas e técnicas de manufatura enxuta em uma instalação de processo (Abdulmalek \& Rajgopal, 2007). Assim, o método de contato implica numa possibilidade importante de ganho para uma indústria que deve evitar ao máximo o desperdício.

Considerando o quesito "método de contato", se "o trabalhador consegue identificar os defeitos em razão de dispositivo de contato ou forma do produto, eliminando o defeito na fabricação?" Os resultados obtidos, apresentados na Figura 1, foram os seguintes:

0 processo de produção apresenta método de contato de acordo com a concepção dos trabalhadores, ou seja, de quem está na linha direta de produção:

Um dos trabalhadores respondeu que não, pois observa que a indústria poderia ampliar os métodos de contato para muitos outros dispositivos, o que poderia ser pensado em termos de aplicação.

Sugere-se a realização de pesquisas mais aprofundadas junto aos trabalhadores, a fim de captar deles sugestões de melhoria contínua do 


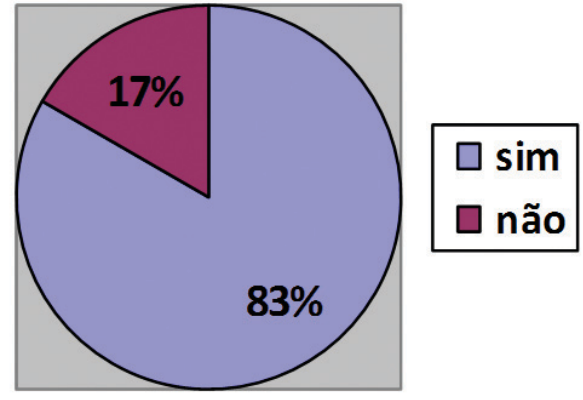

Figura 1. Resultado do quesito 1 do questionário sobre o Método Poka Yoke. Fonte: autor (2012).

processo de produção, especificamente na linha de pesquisa realizada.

No entanto, cabe o cuidado com a adoção de medidas dispendiosas no sistema produtivo.

Como com qualquer outra iniciativa de mudança, implementações zero defeito diferem muito de uma empresa para outra. Alguns dos problemas e as discrepâncias podem ser atribuídos a diferenças no segmento de mercado, processos de produção e competitividade e regulamentação ambiental. No entanto, parece razoável suspeitar que mudanças tão grandes quanto uma implementação discreta são muito influenciadas pela cultura da empresa, seus valores e tradições (Manotas-Duque \& Rivera-Cadavid, 2007).

Passando ao quesito "método de conjunto", no questionamento se "existe um número de atividades a serem cumpridas?", a resposta dos trabalhadores foi uníssona, de que existe um padrão a ser cumprindo, demonstrando que a indústria está coerente com sua proposta de ser eficiente na produção de seus ativos.

Hare (2002 apud Untawale \& Akant, 2009) explica que quando a variação do processo é reduzida, duas coisas acontecem, e que ambas são boas. A primeira é que aumenta o rendimento. Isso significa menos desperdício e menos retrabalho e paradas de linha; a segunda coisa que acontece como resultado da redução da variação é que a qualidade melhora.

Uma vez que as empresas identificam as principais fontes de resíduos, tais como ferramentas de melhoria contínua, e outros irão orientar as empresas através de ações corretivas, de modo a eliminar o desperdício. Uma célula consiste de equipamentos e estações de trabalho que estão dispostas em uma ordem que mantém um fluxo regular de materiais e componentes durante 0 processo. Também é atribuído aos operadores que são qualificados e treinados para trabalhar nessa célula. Organizando pessoas e equipamentos em células trazem grande vantagem em termos de atingir metas enxutas. Uma das vantagens das células é o

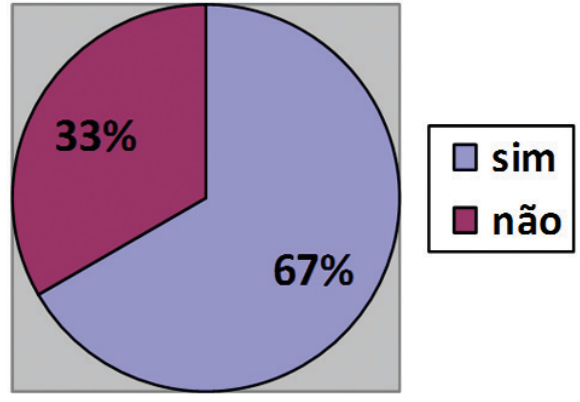

Figura 2. Resultado do quesito 2 do questionário sobre o Método Poka Yoke. Fonte: autor (2012).

conceito de fluxo de uma peça, que afirma que o movimento de cada produto através da unidade de processamento de cada vez, sem interrupção brusca, em um ritmo determinado pela necessidade do cliente. Estendendo o mix de produtos é outra vantagem da fabricação celular (Abdulmalek \& Rajgopal, 2007).

Assim, o planejamento dos passos da produção é uma importante ferramenta e estratégia aplicada ao processo produtivo.

No mesmo quesito de "método de conjunto", sobre se "todas elas são executadas de acordo com o planejamento de produção?”, há pequena discrepância, evidenciada na Figura 2.

Nesse sentido, a ideia de realizar uma pesquisa de clima organizacional se consolida como aspecto auxiliar na compreensão do que os trabalhadores esperam e o que a alta administração está sinalizando como prioridade.

A manutenção produtiva total é uma maneira de eliminar defeitos e desperdícios. Não há dúvida de que a eliminação de resíduos é um ingrediente essencial para a sobrevivência no mundo da fabricação de hoje. As empresas devem se esforçar para criar com alta qualidade produtos de baixo custo que possam chegar aos clientes no menor tempo possível. Há conjuntos de ferramentas que foram desenvolvidas na Toyota e que podem ser utilizadas para eliminar ou pelo menos reduzir as fontes de desperdício (Abdulmalek \& Rajgopal, 2007).

No entanto, qualidade, quantidade e velocidade não são apenas as novas competências que a sociedade exige. Uma vez que o ritmo de mudança da sociedade está se acelerando, a organização deveria também ser capaz de responder às novas exigências, oferecendo novas soluções. A abordagem não significa, naturalmente, que o cliente sempre recebe exatamente o que ele quer. Contudo, as organizações bem-sucedidas usam as necessidades dos clientes e as expectativas como um ponto inicial 
no desenvolvimento de propostas em torno de suas necessidades e das expectativas dos clientes, atendendo também outros imperativos corporativos. Gerenciar a satisfação, portanto, tem a ver com a gestão dos serviços e/ou produtos, mas também com a gestão das expectativas e percepções do cliente. A medição de satisfação parece ser apenas um elemento dessa abordagem de satisfação global de gestão (European Public Administration Network, 2008).

Disciplina, não significa apenas obediência a regras e regulamentos mas inclui autoformação para controlar hábitos e ações, mesmo suportando influências negativas. A imposição da disciplina dá-se através dos colaboradores.

Passando ao quesito método, se "são seguidos os estágios ou operações estabelecidas pelo planejamento da produção?”, os resultados obtidos na pesquisa estão apresentados na Figura 3.

A observação feita pelos trabalhadores é de que poucas vezes, em razão do tempo, é preciso antecipar passos, o que prejudica a qualidade final.

Quanto às observações do quesito se o trabalhador é capaz de identificar os defeitos em função dos dispositivos Poka Yoke, as respostas foram consideradas

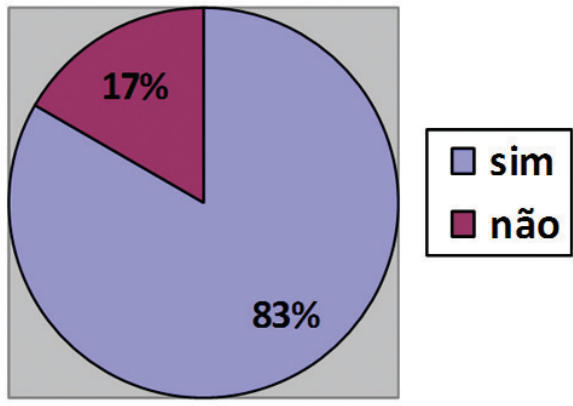

Figura 3. Resultado do quesito 3 do questionário sobre 0 Método Poka Yoke. Fonte: autor (2012).

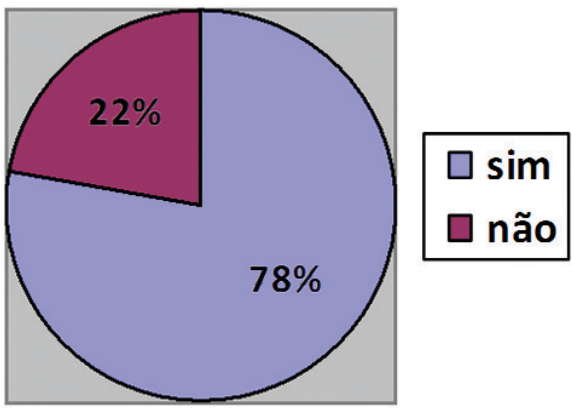

Figura 4. Média de resultados dos quesitos 1,2 e 3 do questionário sobre o Método Poka Yoke. Fonte: autor (2012). satisfatórias, haja vista que eles efetivamente funcionam.

No quesito método de conjunto, em que há um número de atividades a serem cumpridos, os trabalhadores estão cientes dessa realidade.

Numa avaliação global dos resultados pode-se apresentar o seguinte resultado, de acordo com a Figura 4.

Na Figura 4 apresenta-se a percepção dos trabalhadores sobre a metodologia investigada, que se mostra particularmente positiva e com a maioria $(78 \%)$ considerando positivamente o cumprimento dos quesitos.

No entanto, ainda há o que melhorar em termos de seguir à risca o planejamento da produção.

\section{Considerações finais}

Os profissionais devem estar sensibilizados e serem parte do processo, em função de na empresa constituírem

[...] três ativos principais: conhecimentos avançados e especializados; competência para operar segundo os mais altos padrões de qualidade; acesso a recursos em todo o mundo, através de conexões (Santos, 2006, p. 1).

evitando a geração de resíduos e desperdícios na indústria.

As fontes de resíduos são todas relacionadas umas às outras e se livrar de uma fonte de desperdício pode levar à eliminação ou redução em outras. Talvez a mais importante fonte de desperdício seja o inventário. No trabalho em processo e acabados, estoque de peças não agregam valor ao produto e devem ser eliminados ou reduzidos. Quando o estoque é reduzido, os problemas escondidos podem aparecer e medidas podem ser tomadas imediatamente. Há muitas maneiras de reduzir a quantidade de inventário, uma dos quais é reduzindo o tamanho dos lotes de produção. Redução de estoques traz benefícios (Karlsson \& Ahlström, 1996). Na Toyota, Shingo desenvolveu o conceito de troca rápida de matrizes (Smed) para reduzir tempos de setup (Shingo, 1996), por exemplo, tempo de setup em puncionadeiras pôde ser reduzido de horas para menos de dez minutos. lsso teve um efeito grande na redução dos tamanhos de lote (Abdulmalek \& Rajgopal, 2007).

Na pesquisa realizada foi possível verificar a importância dos métodos de qualidade para a indústria.

A qualidade do produto precisa ser confiável ou de acordo com as especificações predeterminadas. Com um tempo de entrega razoável. 0 cliente precisa ter o produto dentro de um determinado período de tempo, caso contrário o produto não tem valor. 
0 valor inovação, na qualidade, é vital para que as empresas enfrentem as mudanças no ambiente $\mathrm{e}$ nas necessidades dos clientes, sendo imperativo que novas ideias sejam introduzidas, a fim de reduzir custos operacionais, salvar tempo, aumentar a produção e a satisfação. Para promover essa cultura de inovação, várias medidas concretas precisam ser realizadas, as quais incluem a introdução da qualidade total num sistema que prevê para os empregados expressarem suas sugestões, estabelecendo grupos de resolução de problemas que trazem os trabalhadores juntos para discutir formas de resolver problemas. Como resultado, podem ocorrer muitas inovações na forma de projetos de produtos e processos tecnológicos e na de práticas de trabalho.

Aproveitando os ensinamentos de Shingo no Poka Yoke e a necessidade maior de ser sustentável, pode-se dizer que a qualidade deve ser a base industrial nos dias atuais.

Esses fatores representam um desafio grande para as empresas, desafiando-as a procurar novas ferramentas para continuar em um mercado global com concorrência crescente. Enquanto algumas empresas continuam a crescer com base na constância econômica, outras empresas lutam por causa de sua falta de compreensão da mudança do cliente, das mentalidades e das práticas de custo. Para sair dessa situação e se tornar mais rentável, muitos fabricantes já começaram a voltar para os princípios da manufatura enxuta para elevar o desempenho de suas empresas. As ideias básicas por trás do sistema de manufatura enxuta que vem sendo praticado há muitos anos no Japão são a eliminação de resíduos, a redução de custos e a capacitação dos funcionários. A filosofia japonesa de fazer negócios é totalmente diferente da filosofia prevalente nos EUA. A crença tradicional no Ocidente é a de que a única maneira de se ter lucro é adicioná-lo ao custo de produção, a fim de se chegar ao preço de venda desejado (Ohno, 1997; Monden, 1998). A abordagem japonesa, ao contrário, acredita que os clientes são os geradores do preço de venda (Abdulmalek \& Rajgopal, 2007).

0 valor produtividade reflete quão bem uma empresa utiliza seus recursos. Oito fatores críticos que influenciam a produtividade foram identificados. Tratam-se de recursos humanos, sistemas e procedimentos, estrutura organizacional, estilo de gestão, ambiente de trabalho, tecnologia, materiais e equipamento de capital. Para melhorar a produtividade, as empresas têm sido direcionadas a implementar várias melhorias no gerenciamento de arquivos, de informações, de processos de trabalho, do design de formulários, do trabalho de medição e sistemas de controle. Além de automação de escritório, e do desenvolvimento de tecnologia intensificada a fim de agilizar e melhorar a qualidade do serviço.

A fim de serem bem-sucedidos no mercado altamente competitivo de hoje, fabricantes dos EUA têm percebido que o conceito tradicional de produção em massa tem de ser adaptado para as novas ideias da manufatura enxuta. Um estudo do movimento da produção em massa para a manufatura enxuta feito no Instituto de Tecnologia de Massachusetts, como explicado no livro A máquina que mudou o mundo (Womack et al., 1990), despertou a indústria norteamericana. 0 estudo ressalta o grande sucesso da Toyota na Nummi (New United Motor Manufacturing Inc.), eliminando o enorme fosso que existia entre as indústrias automotivas japonesas e as ocidentais. As ideias vieram a ser aprovadas nos EUA porque as empresas japonesas desenvolveram, produziram e distribuiram seus produtos com metade ou menos esforço humano, investimento de capital, espaço, ferramentas, materiais, tempo e despesa total que as americanas (Womack et al., 1990; Abdulmalek \& Rajgopal, 2007).

Considerando o quesito método quando se questiona se são seguidos os estágios ou operações estabelecidas pelo planejamento da produção, há uma clara consciência por parte dos trabalhadores da importância de se seguirem as normas.

A qualidade do produto precisa ser confiável ou de acordo com as especificações predeterminadas. Com um tempo de entrega razoável. 0 cliente precisa ter o produto dentro de um determinado período de tempo, caso contrário o produto não tem valor.

Quanto aos objetivos apresentar conceitos e discutir a qualidade do processo de produção na indústria, foram alcançados ao mesmo tempo em que se discorreu sobre os pontos positivos na qualidade na produção e se analisou a importância da gestão da qualidade para a empresa.

Fazer monitoramento tem importância e deve ser focado na satisfação crescente para que o cliente receba um serviço mais completo e melhore a reputação da indústria, que assim pode manter e ampliar seus clientes.

É mais provável que um cliente satisfeito venha a manter um bom relacionamento com a empresa ao longo do tempo e isso é o que realmente interessa, daí a importância de realização da metodologia.

A natureza da satisfação do cliente é específica. Quando se olha para a satisfação do cliente, devem-se fazer perguntas diretamente sobre a prestação de serviços a nível operacional. A prioridade é para os usuários de um serviço/produto melhor. 0 desafio é equilibrar ambos distintamente, e muitas vezes concorrentes, fatores de custo/benefício para os 
cidadãos, com alta qualidade, e serviços acessíveis para os clientes. Não também uma série de características que os produtos diferentes, do setor privado de serviços. Muitos modelos de foco a qualidade do serviço sobre o objetivo de aumentar o consumo de serviços e/ou aumentar a fidelidade do cliente. Para muitas organizações, essas considerações são, em teoria, menos relevantes, como são os fornecedores de monopólio, os clientes são obrigados a consumir os serviços (como os serviços de regulamentação) (European Public Administration Network, 2008).

A análise do sistema Poka Yoke sem dúvida mostrou a importância desse sistema na redução e eliminação de perdas nos processos de fabricação de manufaturas caldeiradas, diminuindo os custos de retrabalho e, dessa maneira, a oneração e o desperdício durante os processos.

Com a utilização desse método, podem-se atingir os objetivos deste trabalho, que eram elucidar como o Poka Yoke pode auxiliar na produção, corrigindo defeitos na execução de peças caldeiradas, buscando a conformidade no processo de fabricação, verificando índices de conformidade das peças fornecidas e descrevendo processos de produção com o uso do sistema Poka Yoke.

Ao fim desta pesquisa, em que os objetivos a serem atingidos com a utilização do Poka Yoke eram contribuir para evitar erros e falhas em caldeiraria, notou-se que tanto a qualidade quanto a conformidade aumentaram significativamente. Os colaboradores que participaram da pesquisa em sua maioria significativa avaliaram de forma positiva o método em questão, e pôde-se comprovar uma maior conformidade para o produto, trazendo confiabilidade para a empresa e, sobretudo, eliminando perdas durante o processo produtivo.

Este artigo científico, ao ser elaborado, buscou identificar os benefícios e as funcionalidades que essa ferramenta apresenta, os quais ainda não haviam sidos mencionados na literatura, no setor específico da caldeiraria, constituindo uma possível contribuição positiva para as empresas que tenham acesso a este trabalho.

Como fator limitante deste trabalho, o tamanho das amostras, assim como o número de empresas envolvidas, que deveriam ser maiores, ao serem realizados trabalhos futuros, para que os dados apresentados possam vir a ser confirmados ou não.

\section{Referências}

Abdulmalek, F. A., \& Rajgopal, J. (2007). Analyzing the benefits of lean manufacturing and value stream mapping via simulation: a process sector case study. International Journal of Production Economics, 1071), 223-236. http://dx.doi.org/10.1016/j.ijpe.2006.09.009
Almeida, H. S., \& Toledo, J. C. (1992). Qualidade total do produto. Produção, 2(1), 21-37.

Antunes, R. (1998). Em direção a uma teoria geral do processo na administração da produção: uma discussão sobre a possibilidade de unificação da teoria das restrições e a teoria que sustenta a construção dos sistemas de produção com estoque zero (Tese de doutorado). Universidade Federal do Rio Grande do Sul, Porto Alegre.

Costa Junior, E. L. (2007). Gestão em processo produtivo. Curitiba: lbpex.

European Public Administration Network - EUPAN. (2008). Customer satisfaction management. EUPAN. Recuperado em 24 de julho de 2012, de http://www.eupan.eu/files/ repository/20101215131727_EU_Primer_English_ FINAL_LR.pdf

Fusco, J. P. A., \& Sacomano, J. B. (2007). Operações e gestão estratégica da produção. São Paulo: Arte \& Ciência.

Ghinato, P. (1996). Sistema Toyota de Produção: mais do que simplesmente Just-in-time. Caxias do Sul: EDUCS.

Gil, A. C. (2002). Como elaborar projeto de pesquisa (2a ed.). São Paulo: Atlas.

Godinho Filho, M., \& Fernandes, F. C. F. (2004). Manufatura enxuta: uma revisão que classifica e analisa os trabalhos apontando perspectivas de pesquisas futuras. Gestão \& Produção, 11(1), 11-19. http://dx.doi.org/10.1590/ S0104-530X2004000100002

Karlsson, C., \& Ahlström, P. (1996). Assessing change towards lean production. International Journal of Operations \& Production Management, 16(2), 24-41. http://dx.doi. org/10.1108/01443579610109820

Imai, M. (1996). Gemba-kaizen: estratégias e técnicas do Kaizen no piso de fábrica. São Paulo: IMAM.

Liker, K. J. (2005). O Modelo Toyota. Porto Alegre: Bookman.

Manotas-Duque, D. F., \& Rivera-Cadavid, L. (2007). Lean manufacturing measurement: the relationship between lean activities and lean metrics. Estudios Gerenciales, 23(105), 69-83. http://dx.doi.org/10.1016/ S0123-5923(07)70026-8

Monden, Y. (1984). Sistema Toyota de Produção. São Paulo: IMAM.

Monden, Y. (1998). Toyota Production System: an integrated approach to Just-In-Time. Norcross: Institute of Industrial Engineers.

Moura, A. R., \& Banzato, J. M. (1996). Poka-Yoke: a eliminação dos defeitos com o método à prova de falhas. São Paulo: Iman.

Ohno, T. (1997). O Sistema Toyota de Produção: além da produção em larga escala. Porto Alegre: Bookman.

Rebelato, M. G., \& Oliveira, I. S. (2006). Um estudo comparativo entre a Gestão da Qualidade Total (TQM), o Seis Sigma e a ISO 9000. Revista Gestão Industrial, 2(1),106-116.

Santos, M. T. (2006). O PLM: gerenciamento do ciclo de vida do produto transformando negócios em empresas classe mundial. Zona Industrial Norte: Brasilmatics.

Silva, G. G. M. P. (2009). Implantando a manufatura enxuta: um método estruturado (Dissertação de mestrado). Universidade Federal de Santa Catarina, Florianópolis.

Schiffman, L., \& Kanuk, L. (2000). Comportamento do consumidor ( $6^{\mathrm{a}}$ ed.). Rio de Janeiro: LTC. 
Sellito, M. A. (2000). Sistema Toyota de produção: é possível aplicá-lo na indústria calçadista? Revista Tecnicouro, 21(7), 23-27.

Shimbun, N. K. (1988). Poka-Yoke: improving product quality by preventing defects. Cambridge: Productivity Press.

Shingo, S. (1996). O Sistema Toyota de Produção: do ponto de vista da engenharia de produção. Porto Alegre: Bookman. PMid:8905671

Untawale, S. P., \& Akant, S. S. (2009). Quality and productivity linking methodologies for industries using SPSS (Statistical Package for Social Sciences). Perlis: Universiti Malaysia Perlis.
Valls, V. M. (2004). 0 enfoque por processos da NBR ISO 9001 e sua aplicação nos serviços de informação. Ciência da Informação, 33(2), 172-178. http://dx.doi.org/10.1590/ S0100-19652004000200018

Vergara, S. C. (2003). Projetos e relatórios de pesquisa em Administração (4.). São Paulo: Atlas.

Womack, J. P., \& Jones, D. T. (2004). A mentalidade enxuta nas empresas: elimine o desperdício e crie riquezas (6 ed.). Rio de Janeiro: Elsevier.

Womack, J. P., Jones, D. T., \& Ross, D. (1990). The machine that changed the World. New York: Rawson Associates.

\title{
The application of the Poka-Yoke method in the manufacturing of steel structures
}

\begin{abstract}
This paper aims to demonstrate that the Poka-Yoke method helps avoid errors and correct defects in the execution of parts of the steel structure. As the justification for the choice of this theme emphasizes, companies increasingly invest in the quality of production processes because waste signals failure, and the mechanisms of investigation as the means of control must be increasingly improved. The line of research used for this study is that systemization of the spot will occur as the process flow of the Poka-Yoke method is applied to parts stews. The methodology will be set in steps of control, including quantitatively and qualitatively evaluating errors and the failures that identify the processes and the production improvements and will assess the reworking such that this process occurs in controlling production line efficiency. Note that this work serves as a tool for Production Engineering geared to the management process, thus including the main focus of the training that the university where this study was conducted particularized. Was seen in the research that the system works even when there is an awareness of workers about the importance of the methodology applied in production processes. In this study, the system works even when workers are aware of the importance of the methodology that is applied in production processes.
\end{abstract}

Keywords

Poka-Yoke. Lean production. Quality. 